\title{
Wound Dehiscence, CTCAE
}

National Cancer Institute

\section{Source}

National Cancer Institute. Wound Dehiscence, CT CAE. NCI Thesaurus. Code C143950.

A finding of separation of the approximated margins of a surgical wound. 